\title{
A thermally-induced, tandem [3,3]-sigmatropic rearrangement/[2 + 2] cycloaddition approach to carbocyclic spirooxindoles
}

\author{
Kay M. Brummond ${ }^{*}$ and Joshua M. Osbourn
}

\section{Preliminary Communication}

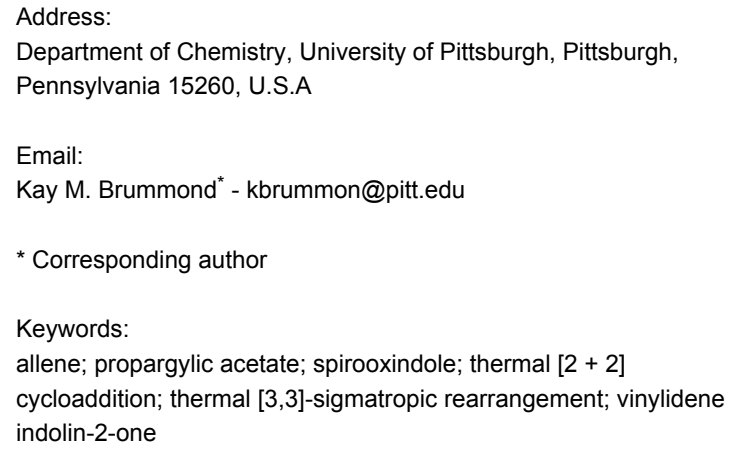

Beilstein Journal of Organic Chemistry 2010, 6, No. 33 doi:10.3762/bjoc.6.33

Received: 19 February 2010

Accepted: 31 March 2010

Published: 08 April 2010

Associate Editor: J. Aubé

(c) 2010 Brummond and Osbourn; licensee Beilstein-Institut. License and terms: see end of document.

\begin{abstract}
The synthesis of C3-carbocyclic spirooxindoles was realized by way of an intramolecular [2+2] cycloaddition reaction between a vinylidene indolin-2-one and an alkyne. The cycloaddition reaction occurs selectively with the distal double bond of the allene, is tolerant of a phenyl and trimethylsilyl group on the terminus of the alkyne, and can be used to access bicyclo[4.2.0]octadienes and bicyclo[5.2.0]nonadienes. The allene precursors are not observed, but are likely intermediates of an infrequently encountered thermal [3,3]-sigmatropic rearrangement of a propargylic acetate.
\end{abstract}

\section{Introduction}

Spirooxindoles are structural motifs containing a heterocycle or carbocycle at the $\mathrm{C} 3$ position of an oxindole. Particularly well known are the pyrrolidinyl-spirooxindoles $\mathbf{1}$ which have been classified as a privileged motif due to their presence in a large number of heterocyclic alkaloids (Figure 1) [1]. Spirotryprostatin B (2) is just one example of many natural products from this class exhibiting interesting biological activity [2]. Compounds possessing a carbocycle at the $\mathrm{C} 3$ position of the oxindole, such as $\mathbf{3}$, are less common and spirooxindoles containing a four carbon spirocycle are rare. One notable natural product containing this basic skeleton is welwitindolinone A isonitrile (4); a compound that has recently captured the attention of the synthetic community $[3,4]$.

Spiro[cyclobutane-1,3'-indolin]-2'-ones $(\mathbf{3}, n=0)$ have previously been prepared but the synthetic approach is mostly limited to simple spirocyclobutanes that are accessed via alkylation chemistry [5]. Alternatively, more structurally complex spirocyclobutanes have been obtained from homodimerization reactions of allenes or alkenes [6,7]. However, neither of these 
<smiles>O=C1Nc2ccccc2[C@]12CCNC2</smiles>

1

C3 pyrrolidiny spirooxindole<smiles>CC1=CC(=O)[C@]2(C=C3C(=O)N4CCC[C@H]4C(=O)N3C2=O)c2ccccc2N1</smiles>

2

spirotryprostatin B<smiles>O=C1Nc2ccccc2C12CCCC2</smiles>

3

C3 carbocyclic

spirooxindole

$(n=0-3)$<smiles>C=C[C@]1(C)C(C)=C([C@]2(C(C)(C)C)C(=O)Nc3ccccc32)[C@H](C)C[C@H]1Cl</smiles>

4

welwitindolinone A

isonitrile

Figure 1: Heterocyclic and carbocyclic spirooxindoles.

approaches provides an enabling strategy for accessing the densely functionalized and unsymmetrical molecular architectures of many of the natural products possessing this oxindoline core. We anticipated that access to this class of compounds utilizing chemistry developed in our laboratories would provide an expansion of substructures within this chemical space, thus enhancing the discovery of new biological probes and pharmaceuticals [8].

We recently disclosed a thermal $[2+2]$ cycloaddition reaction of allene-ynes to provide a variety of alkylidene cyclobutenes in good yields [9-18]. Notable features of this reaction were the stability of the resulting alkylidene cyclobutenes, the regioselectivity for reaction of the distal double bond of the allene, and ready cyclization of substrates possessing heteroatom tethers to give heterocyclic structures (Scheme 1) [19-26]. Inspired by the unique skeleton of welwitindolinone $\mathrm{A}$, the feasibility of this method for the preparation of spirooxindole alkaloids was investigated. The preliminary results of this study are reported herein.

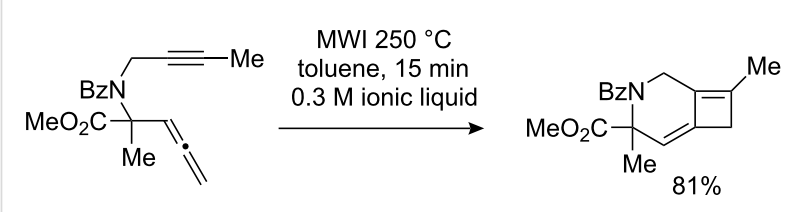

Scheme 1: A thermal $[2+2]$ cycloaddition reaction.

\section{Results and Discussion}

To begin the investigation, the first challenge was the preparation of a functionalized vinylidene indolin-2-one 5 (Figure 2). There is only one report of this allene substructure in the literature and it was not particularly well suited for the incorporation of additional functionality [6]. Scattered reports of propargylic acetates thermally rearranging to allenyl acetates exist, thus, it was reasoned that the allene moiety of $\mathbf{5}$ could be obtained by way of a thermal [3,3]-sigmatropic rearrangement of the propargylic acetate $\mathbf{6}$ to give compound $\mathbf{5}$ where $\mathrm{R}^{2}=\mathrm{OAc}$ (Figure 2) [27].<smiles>[R]C([R])=C1C(=O)Nc2ccccc21</smiles>
5<smiles>[R]C#C[C@]1(C#C)C(=O)Nc2ccccc21</smiles>

6
Figure 2: Access to vinylidene indolin-2-ones.

Preparation of propargylic acetate 9a was accomplished by the addition of the lithium acetylide of 8 to $N$-methyl isatin (7) followed by acetylation of the resulting propargyl alcohol. Heating propargylic acetate 9a to $225^{\circ} \mathrm{C}$ in 1,2-dichlorobenzene in the microwave for $30 \mathrm{~min}$ gave the spirooxindole 10a in $60 \%$ yield (Scheme 2). Structural confirmation of 10a was<smiles>CN1C(=O)C(=O)c2ccccc21</smiles>
7<smiles>C#CCCCC#Cc1ccccc1</smiles>

n-BuLi, THF, $-78{ }^{\circ} \mathrm{C} 66 \%$ 2. $\mathrm{Ac}_{2} \mathrm{O}, \mathrm{DMAP}, \mathrm{NEt}_{3} 98 \%$<smiles>CCCC#CCCCC#CC1(O)C(=O)Nc2ccccc21</smiles>

9a
$\mathrm{MWI}, 225^{\circ} \mathrm{C}$ $\underset{\text { 1,2-dichlorobenzene }}{\longrightarrow}$ $30 \min 60 \%$ $\mathrm{AcO}$<smiles>CC(=O)OC1=C2CCC=C2C1(C(=O)O)c1ccccc1</smiles>

10a 
achieved using COSY, HMQC and HMBC. Attempts to effect the [3,3]-sigmatropic rearrangement of the propargyl acetate 9a using transition metal catalysis $\left(\mathrm{AuCl}_{3} 10 \mathrm{~mol} \%\right.$, toluene, $1 \mathrm{~h}$, rt) led to hydrolysis of the allenyl acetate functionality.

This densely functionalized alkylidene cyclobutene 10a is postulated to arise via the $[2+2]$ cycloaddition reaction between the alkyne and the allenyl acetate in intermediate $\mathbf{1 1}$ which in turn arises from the thermal [3,3]-sigmatropic rearrangement of 9a (Figure 3).

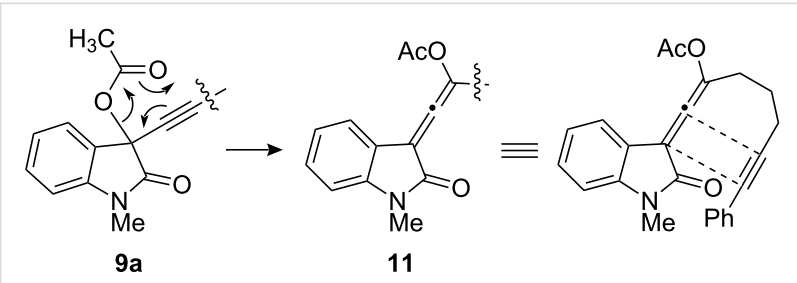

Figure 3: A tandem [3,3]-sigmatropic rearrangement/[2 + 2] cycloaddition.

We have briefly investigated the scope and limitations of this tandem cycloaddition reaction by varying the protecting group on the oxindole nitrogen, altering the substitution on the alkyne terminus and increasing the number of carbon atoms in the tether. Groups such as methyl (Me), methoxymethyl (MOM), and 2-(trimethylsilyl)ethoxymethyl (SEM) were found to be well tolerated. Substrates possessing either a phenyl or a silyl group on the alkyne terminus also gave good yields of the spirooxindoles. However, when a terminal alkyne was subjected to the reaction conditions, only decomposition of the starting material was observed (entry 3, Table 1). When $N$-methylpyrrolidinone (NMP) was used as a solvent the reaction mixture could be heated to higher temperatures $\left(250^{\circ} \mathrm{C}\right.$ vs. $225^{\circ} \mathrm{C}$ in 1,2-dichlorobenzene) and the reaction times were shorter which had a marginal affect on the yield of the reaction (compare entries 5 and 6). A further advantage of NMP over 1,2-dichorobenzene was the ease of isolation of the products since the solvent could be removed with aqueous washings instead of column chromatography. To investigate the yield of this reaction the transformation of propargyl acetate $9 f$ to spirooxindole $10 f$ was monitored by proton NMR. We found that the NMR yield is consistent with the isolated yield and the source of lost mass is attributed to decomposition during the course of the reaction as evidenced by baseline impurities on the TLC. However, the only discernable product in the NMR spectrum is the desired spirooxindole $\mathbf{1 0 f}$.

\section{Conclusion}

We have developed a concise synthesis to C3-carbocyclic spirooxindoles. One important feature of this thermal tandem $[3,3]$-sigmatropic rearrangement/[2 +2$]$ cycloaddition reaction is that the reaction remains selective for the distal double bond of the allene even with densely functionalized allenes [29]. In addition, conversion of the propargylic acetate to the spirooxindole in one step provides a rapid and potentially stereoselective increase in molecular complexity. Furthermore, this approach includes a rare example of a thermal [3,3]-sigmatropic rearrangement of a propargylic acetate while metal catalyzed rearrangements of the propargyl acetates are common. Work is currently underway to expand the synthetic utility of this reaction.

Table 1: Synthesis of spirooxindoles.

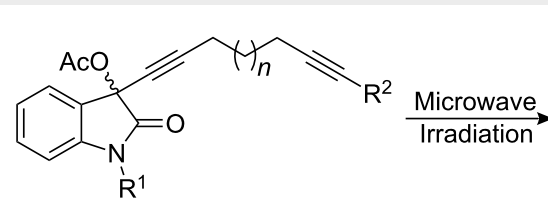

9a-f

\begin{tabular}{lll} 
Entry & $\mathrm{R}^{1}$ & $\mathrm{R}^{2}$ \\
\hline 1 & $\mathrm{Me}$ & $\mathrm{Ph}$ \\
2 & $\mathrm{Me}$ & $\mathrm{TMS}$ \\
3 & $\mathrm{Me}$ & $\mathrm{H}$ \\
4 & $\mathrm{SEM}$ & $\mathrm{Ph}$ \\
5 & $\mathrm{MOM}$ & $\mathrm{Ph}$ \\
6 & MOM & $\mathrm{Ph}$ \\
7 & MOM & $\mathrm{Ph}$ \\
\hline
\end{tabular}

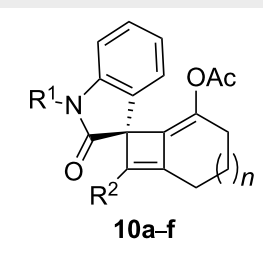

n Solvent ${ }^{\mathrm{a}} \quad$ Temp Time

\begin{tabular}{ll} 
Product & Yield \\
\hline 10a & $60 \%$ \\
10b & $50 \%$ \\
$10 \mathrm{c}$ & $0 \%$ \\
$10 \mathrm{~d}$ & $61 \%$ \\
$10 \mathrm{e}$ & $57 \%$ \\
$10 \mathrm{e}$ & $61 \%$ \\
$10 \mathrm{f}$ & $48 \%$
\end{tabular}

aln our original report, the most successful solvent system for the cycloaddition was toluene doped with an ionic liquid (0.3 M). However we have moved away from this solvent system because subsequent to that study, two sample solutions (out of hundreds), that were allowed to age for an hour prior to microwave irradiation, immediately exploded upon irradiation. Oliver Kappe has made similar observations when using ionic liquids in the presence of ethylene gas in the microwave. Kappe demonstrated that the explosion is due to the ionic liquid initiating an exothermic polymerization reaction [28]. We suspect that the ionic liquid initiated a polymerization reaction of the allene-ynes when allowed to stand prior to irradiation. 


\section{Experimental}

Spirooxindole (10a) Propargyl acetate 9 (30 mg, $0.081 \mathrm{mmol})$ was dissolved in 1,2-dichlorobenzene $(1.62 \mathrm{~mL})$ in a $0.5-2 \mathrm{~mL}$ Biotage $^{\mathrm{TM}}$ microwave vial. The vial was capped and the solution irradiated in the microwave for $30 \mathrm{~min}$ at $225^{\circ} \mathrm{C}$. The reaction mixture was diluted with hexane $(2 \mathrm{~mL})$ and applied to a silica gel column. The column was eluted with hexanes (100 $\mathrm{mL}$ ) and then with $25 \%$ ethyl acetate/hexanes. The fractions containing the desired product were concentrated under reduced pressure to provide $18 \mathrm{mg}$ of spirooxindole $\mathbf{1 0 a}$ as a brown oil in $60 \%$ yield.

\section{Supporting Information}

General methods, experimental and spectral data are provided for all new compounds in the Supporting Information.

\section{Supporting Information File 1}

General methods, experimental and spectral data. [http://www.beilstein-journals.org/bjoc/content/ supplementary/1860-5397-6-33-S1.pdf]

\section{Acknowledgements}

Generous support from the National Science Foundation is gratefully acknowledged (NSF 0910597).

\section{References}

1. Galliford, C. V.; Scheidt, K. A. Angew. Chem., Int. Ed. 2007, 46, 8748. doi:10.1002/anie.200701342

2. Cui, C.-B.; Kakeya, H.; Osada, H. Tetrahedron 1996, 52, 12651. doi:10.1016/0040-4020(96)00737-5

3. Baran, P. S.; Richter, J. M. J. Am. Chem. Soc. 2005, 127, 15394. doi:10.1021/ja056171r

4. Reisman, S. E.; Ready, J. M.; Hasuoka, A.; Smith, C. J.; Wood, J. L. J. Am. Chem. Soc. 2006, 128, 1448. doi:10.1021/ja057640s

5. Stevens, F. C.; Bloomquist, W. E.; Borel, A. G.; Cohen, M. L.; Droste, C. A.; Heiman, M. L.; Kriauciunas, A.; Sall, D. J.; Tinsley, F. C.; Jesudason, C. D. Bioorg. Med. Chem. Lett. 2007, 17, 6270. doi:10.1016/j.bmcl.2007.09.011

6. Beccalli, E.; Marchesini, A.; Pilati, T. Tetrahedron 1994, 50, 12697. doi:10.1016/S0040-4020(01)89402-3

7. Milanesio, M.; Viterbo, D.; Albini, A.; Fasani, E.; Bianchi, R.; Barzaghi, M. J. Org. Chem. 2000, 65, 3416. doi:10.1021/jo991873i

8. Lipkus, A. H.; Yuan, Q.; Lucas, K. A.; Funk, S. A.; Bartelt, W. F.; Schenck, R. J.; Trippe, A. J. J. Org. Chem. 2008, 73, 4443. doi:10.1021/jo8001276

9. Murakami, M.; Amii, H.; Itami, K.; Ito, Y. Angew. Chem., Int. Ed. Engl. 1995, 34, 1476. doi:10.1002/anie.199514761

10. Friesen, R. W.; Dubé, D.; Fortin, R.; Frenette, R.; Prescott, S.; Cromlish, W.; Greig, G. M.; Kargman, S.; Wong, E.; Chan, C. C.; Gordon, R.; Xu, L. J.; Riendeau, D. Bioorg. Med. Chem. Lett. 1996, 6, 2677. doi:10.1016/S0960-894X(96)00501-X
11. Lopez, S.; Rodriguez, J.; Rey, J. G.; de Lera, A. R. J. Am. Chem. Soc. 1996, 118, 1881. doi:10.1021/ja9522241

12. Delas, C.; Urabe, H.; Sato, F. J. Am. Chem. Soc. 2001, 123, 7937. doi:10.1021/ja016307v

13. Paih, J. L.; Dèrien, S.; Bruneau, C.; Demerseman, B.; Toupet, L.; Dixneuf, P. H. Angew. Chem., Int. Ed. 2001, 40, 2912. doi:10.1002/1521-3773(20010803)40:15<2912::AID-ANIE2912>3.0.CO ;2-R

14. Murakami, M.; Ashida, S.; Matsuda, T. J. Am. Chem. Soc. 2004, 126, 10838. doi:10.1021/ja046429y

15. Paih, J. L.; Dérien, S.; Demerseman, B.; Bruneau, C.; Dixneuf, P. H.; Toupet, L.; Dazinger, G.; Kirchner, K. Chem.-Eur. J. 2005, 11, 1312. doi:10.1002/chem.200400899

16. Song, Z.; Li, Y.; Liu, M.; Cong, L.; Liu, Y. Organometallics 2006, 25 , 5035. doi:10.1021/om060505j

17. Ramanathan, S.; Lemal, D. M. J. Org. Chem. 2007, 72, 1570. doi:10.1021/jo061946f

18. Yao, L.-F.; Shi, M. Org. Lett. 2007, 9, 5187. doi:10.1021/ol7022592

19. Brummond, K. M.; Chen, D. Org. Lett. 2005, 7, 3473. doi:10.1021/ol051115g

20. Oh, C. H.; Gupta, A. K.; Park, D. I.; Kim, N. Chem. Commun. 2005, 5670. doi:10.1039/b508306k

21. Oh, C. H.; Park, D. I.; Jung, S. H.; Reddy, V. R.; Gupta, A. K.; Kim, Y. M. Synlett 2005, 2092. doi:10.1055/s-2005-871958

22. Ohno, H.; Mizutani, T.; Kadoh, Y.; Miyamura, K.; Tanaka, T. Angew. Chem., Int. Ed. 2005, 44, 5113. doi:10.1002/anie.200501413

23. Mukai, C.; Hara, Y.; Miyashita, Y.; Inagaki, F. J. Org. Chem. 2007, 72, 4454. doi:10.1021/jo070513p

24. Ohno, H.; Mizutani, T.; Kadoh, Y.; Aso, A.; Miyamura, K.; Fujii, N.; Tanaka, T. J. Org. Chem. 2007, 72, 4378. doi:10.1021/jo0700528

25. Buisine, O.; Gandon, V.; Fensterbank, L.; Aubert, C.; Malacria, M. Synlett 2008, 751. doi:10.1055/s-2008-1032113

26. Ovaska, T. V.; Kyne, R. E. Tetrahedron Lett. 2008, 49, 376. doi:10.1016/j.tetlet.2007.11.042

27. Oelberg, D. G.; Schiavelli, M. D. J. Org. Chem. 1977, 42, 1804 doi:10.1021/jo00430a031

28. Van der Eycken, E.; Appukkuttan, P.; De Borggraeve, W.; Dehaen, W.; Dallinger, D.; Kappe, C. O. J. Org. Chem. 2002, 67, 7904. doi:10.1021/jo0263216

29. Saito, N.; Tanaka, Y.; Sato, Y. Organometallics 2009, 28, 669. doi:10.1021/om801181a 


\section{License and Terms}

This is an Open Access article under the terms of the Creative Commons Attribution License

(http://creativecommons.org/licenses/by/2.0), which permits unrestricted use, distribution, and reproduction in any medium, provided the original work is properly cited.

The license is subject to the Beilstein Journal of Organic Chemistry terms and conditions:

(http://www.beilstein-journals.org/bjoc)

The definitive version of this article is the electronic one which can be found at:

doi:10.3762/bjoc.6.33 